\title{
NOTES FROM PRACTICE
}

\section{UIT DIE PRAKTYK}

\section{ON BEING A CLIENT}

Last month a social worker whom I had never met, and with whom I was having my first contact as a client (per telephone) said to me, as an opening statement, "Well, first of all I need to tell you that I think you are crazy!"

This unqualified statement, the first step of the first dance on the dance card shared by client and social worker, was my introduction to social work clienthood. A qualified professional, who did not know me, responds to my tentative and fragile emerging clienthood with a statement of that nature. Where do you go from there? Accept the second dance on the dance card? Probably not.

So how did this conversation start? I had decided, after some time, and together with my life's partner, to foster a child. We had spent time working over this process and had identified a child with whom we had been in contact. The social worker was based at the children's home - I had called the previous day to talk about our decision, seeking guidance and support for what we considered an exciting journey and new phase in our lives. I had left a message but had not had a reply - thus this call.

The conversation's opening struck me like a "stomp" on the toe during a clumsy dance. We continued our clumsy dance throughout that telephone conversation. By the end of it my toes were bruised, my "clienthood" questioning the value system that had guided the person and the profession with which I would now need to engage in intense interaction.

What is a client then, I wondered?... So to the texts I went. Zastrow (1995:92), in something of a classic, I believe, cited the even more classic Pincus and Minahan, suggesting that a client is a person who sanctions and asks for the services of a social worker (or more glamorously, "change agent"). "Some change!" I wondered. From sane to crazy in one quick step! But more about this client/change agent relationship.

I asked myself what the nature of it should be. Vass (1999:43), writing specifically about social work competencies, suggested that the client be respected, seen as a person with specific needs and interests that should not be generalised or assumed. I was assumed to be "crazy". Is there any respect in that assumption? I read further. Heron (1998:11) would also probably be considered crazy by the social worker in question - he suggests that social workers should have what he terms "helping grace" - warm concern and acceptance, openness, a grasp of what the other person needs for his or her flourishing, and, hold your breath, the ability to facilitate the realisation!

So - was my experience just an isolated one? Was it just a "wrong time, wrong day, wrong side of the bed experience"? Perhaps. But can you use my experience in any way to think critically about how clients are "treated"? I hope so. Can we revisit the notion of "clienthood" and begin to understand the fear, anticipation, tension, bravery and often desperation of those who you call 
"your" clients when they first approach you. Can we consider their strengths rather than assume their deficits? Can we stop calling them crazy? Please.

\title{
REFERENCES
}

HERON, J 1998. Helping the Client: A Creative Practical Guide. Sage: London.

VASS, AA (Ed) (1999). Social Work Competencies: Core Knowledge, Values and Skills. Sage: London.

ZASTROW, C. (1995). The Practice of Social Work (5th ed). Brooks/Cole: Pacific Grove.

\author{
A. St John ${ }^{4}$
}

4 The identity of the author is withheld by request and in the interests of family privacy. 